\title{
Regulation of prostaglandin biosynthesis by interleukin-1 in cultured bovine endometrial cells
}

\author{
Michiyo Tanikawa ${ }^{1,5}$, Hwa-Yong Lee ${ }^{1}$, Kikuko Watanabe ${ }^{2}$, Magdalena Majewska ${ }^{3}$, Dariusz J Skarzynski ${ }^{3}$, \\ Soo-Bong Park ${ }^{4}$, Dong-Seok Lee ${ }^{5,6}$, Choon-Keun Park ${ }^{5}$, Tomas J Acosta ${ }^{1}$ and Kiyoshi Okuda ${ }^{1}$ \\ ${ }^{1}$ Laboratory of Reproductive Endocrinology, Graduate School of Natural Science and Technology, Okayama University, Okayama 700-8530, Japan \\ ${ }^{2}$ Division of Applied Life Science, Graduate School of Integrated Science and Art, University of East Asia, Shimonoseki, Yamaguchi 751-8503, Japan \\ ${ }^{3}$ Department of Reproductive Immunology, Institute of Animal Reproduction \& Food Research, Polish Academy of Sciences, Olstzyn 10-747, Poland \\ ${ }^{4}$ National Institute of Animal Science, Suwon 441-706, South Korea \\ ${ }^{5}$ Department of Animal Biotechnology, College of Animal Life Science, Kangwon National University, Chunchon 200-701, South Korea \\ ${ }^{6}$ School of Life Sciences \& Biotechnology, College of Natural Sciences, Kyungpook National University, Daegu 702-701, South Korea \\ (Correspondence should be addressed to T J Acosta; Email: acosta@cc.okayama-u.ac.jp)
}

\begin{abstract}
Interleukin-1 (IL1) has been shown to be a potent stimulator of prostaglandin (PG) production in bovine endometrium. The aim of the present study was to determine the cell types in the endometrium (epithelial or stromal cells) responsible for the secretion of PGE2 and PGF2 $\alpha$ in response to IL1A, and the intracellular mechanisms of IL1A action. Cultured bovine epithelial and stromal cells were exposed to IL1A or IL1B $(0 \cdot 006-3 \cdot 0 \mathrm{nM})$ for $24 \mathrm{~h}$. IL1A and IL1B dose-dependently stimulated PGE2 and PGF $2 \alpha$ production in the stromal cells, but not in the epithelial cells. The stimulatory effect of IL1A $(0 \cdot 06-3 \cdot 0 \mathrm{nM})$ on PG production was greater than that of IL1B. The stimulatory actions of IL1A on PG production was augmented by supplementing arachidonic acid (AA). When the stromal cells were incubated with IL1A and inhibitors of phospholipase (PL) C or PLA2 (1 $\mu \mathrm{M}$; anthranilic acid), only PLA2 inhibitor completely stopped the stimulatory action of
\end{abstract}

IL1A on PG production. Moreover, a specific cyclooxygenase-2 (COX2) inhibitor blocked the stimulatory effect of IL1A on PG production. IL1A $(0 \cdot 06 \mathrm{nM})$ promoted COX2 and microsomal PGE synthase-1 (PGES1) gene and its protein expression. The expression of COX1, PGES2, PGES3, and PGF synthase (PGFS) mRNA was not affected by IL1A in the stromal cells. The overall results indicate that 1) the target of IL1A and IL1B for stimulating both PGE2 and PGF2 $\alpha$ production is the stromal cells, 2) IL1A is a far more potent stimulator than IL1B on PG production in stromal cells, 3) the stimulatory effect of IL1A on PG production is mediated via the activation of PLA2 and COX2, and (4) IL1A induced PG production by increasing expressions of COX2 and PGES1 mRNAs and their proteins in bovine stromal cells.

Journal of Endocrinology (2008) 199, 425-434

\section{Introduction}

The cyclic nature of the bovine estrous cycle depends on the uterine prostaglandin $\mathrm{F} 2 \alpha$ (PGF2 $\alpha$ ) and its action on the corpus luteum (Okuda et al. 2002). PGF2 $\alpha$ is well recognized as the main luteolytic agent in ruminants, whereas PGE2 (PGE2) has luteotropic and luteoprotective properties (Reynold et al. 1981, Weems et al. 1998). Although both PGE2 and PGF2 $\alpha$ are secreted by bovine endometrium throughout the estrous cycle (Miyamoto et al. 2000, Murakami et al. 2001), the relative proportion of PGE2 and PGF $2 \alpha$ secretion is thought to be more important than the absolute amounts of each PG to exert their own physiological effects on the female reproductive function (Murakami et al. 2001). Moreover, we have recently shown that PG production by bovine endometrium is differently regulated by interleukin-1 $\alpha$ (IL1A) throughout the estrous cycle (Tanikawa et al. 2005), suggesting that IL1A plays roles in the local control of PGE2 and PGF $2 \alpha$ production in bovine endometrium during the estrous cycle. IL1B, which is an isomer of IL1A with action through the same receptor and similar biological activity (Dinarello 1988, 1991), also stimulated PG synthesis in bovine endometrial stromal and epithelial cells (Betts \& Hansen 1992, Davidson et al. 1995). In addition, the presence of IL1B in bovine reproductive tract has been demonstrated by immunohistochemistry (Paula-Lopes et al. 1999). Thus, IL1A and IL1B appear to be important in regulating bovine endometrial function. However, the mechanisms involved in the differential effects of both IL1 on PGE2 and PGF2 $\alpha$ production remains to be unknown.

The bovine endometrium is a complex tissue and consists mainly of epithelial and stromal cells (Fortier et al. 1988). Endometrial epithelial cells have been demonstrated to synthesize mainly PGF2 $\alpha$, whereas endometrial stromal cells synthesize approximately ten times more luteotropic PGE2 
than epithelial cells (Kim \& Fortier 1995, Asselin et al. 1996, Skarzynski et al. 2000). Therefore, it is also important to investigate the specific action of IL1A and IL1B on endometrial epithelial and stromal cells in order to understand the local control of PGE2 and PGF $2 \alpha$ production in bovine endometrium by IL1A and IL1B.

PGs are produced from arachidonic acid (AA) liberated from phospholipid stores through the action of phospholipases (PLs; Burgoyne \& Morgan 1990). In bovine luteal cells (Townson \& Pate 1994), IL1B appears to require the stimulation of PL and/or the metabolism of AA for the production of PGs. Moreover, in the bovine uterus, cyclooxygenase-2 (COX2) converts AA to PGH2 (Asselin et al. 1997), which is then converted by PGE synthase (PGES) and PGF synthase (PGFS) to PGE2 and PGF2 $\alpha$ respectively (Madore et al. 2003, Parent \& Fortier 2005). Recently, the existence of at least three different forms of PGES (PGES1, PGES2, and PGES3) have been reported; among them, microsomal PGES-1 (PGES1) was found to be the main enzyme associated with cytokine-induced PGE2 production in the bovine endometrium in vitro (Parent \& Fortier 2005). This enzyme is highly inducible along with COX2 (Madore et al. 2003, Parent \& Fortier 2005). PGFS has recently been identified in bovine endometrium (Madore et al. 2003, Woclawek-Potocka et al. 2005). Since IL1A regulates the PGE2:PGF2 $\alpha$ ratio in bovine endometrium (Tanikawa et al. 2005), and IL1B stimulates PG synthesis in bovine endometrial cells (Betts \& Hansen 1992, Davidson et al. 1995), we hypothesized that IL1A and IL1B have the ability to increase the production of endometrial PGE2 and PGF2 $\alpha$ by modulating key enzymes directly involved in PG biosynthesis pathways.

To address the above hypothesis, we investigated 1) the effect of IL1A and IL1B on PGE2 and PGF2 $\alpha$ synthesis in cultured bovine endometrial epithelial and stromal cells, especially focusing on 2) the effects of IL1 on expression of key enzymes directly involved in PG biosynthesis such as COX, PGES, and PGFS. 3) The intracellular mechanisms involved in IL1 action on PG synthesis via PL A2 and PL C were also studied.

\section{Materials and Methods}

\section{Isolation of endometrial cells}

Uteri of Holstein cows were obtained from a local abattoir in accordance with protocols approved by the local institutional animal care and use committee. The estrus was synchronized using implants of a progesterone analogue (Crestar, Intervet, Holland), with additional injection of an analogue of PGF2 $\alpha$ (cloprostenol; Bioestrophan, Biowet, Gorzow Wielkopowski, Poland), as recommended by the manufacturer for the estrus synchronization of multiparous cows (Bah et al. 2006). In this study, uteri of the early luteal phase (days 2-5) were used. Uteri were obtained within $30 \mathrm{~min}$ after exsanguination and were transported to the laboratory within $1-1.5 \mathrm{~h}$ on ice. The epithelial and stromal cells from the bovine endometrium were separated using procedures described previously (Skarzynski et al. 2000). A polyvinyl catheter was inserted into the side of the oviduct, and the ends of the horn were tied in order to retain trypsin solution for detaching the epithelial cells as described below. The uterine lumen was washed thrice with $30-50 \mathrm{ml}$ of sterile $\mathrm{Ca}^{2+}$ - and $\mathrm{Mg}^{2+}$-free Hank's balanced salt solution (HBSS) supplemented with $100 \mathrm{IU} / \mathrm{ml}$ penicillin, $100 \mu \mathrm{g} / \mathrm{ml}$ streptomycin, and $0 \cdot 1 \%(\mathrm{w} / \mathrm{v})$ BSA (Roche Diagnostics). Thirty to fifty milliliters of sterile HBSS containing $0 \cdot 3 \%$ (w/v) trypsin (Sigma) was then infused into the uterine lumen through the catheter. Epithelial cells were isolated by incubation at $38^{\circ} \mathrm{C}$ for $60 \mathrm{~min}$ with gentle shaking.

After collection of the epithelial cells, the uterine lumen was washed with sterile HBSS supplemented with antibiotics and $0 \cdot 1 \%(\mathrm{w} / \mathrm{v})$ BSA. The horn was then cut transversely with scissors into several segments, which were slit to expose the endometrial surface. Intercaruncular endometrial strips were dissected from the myometrial layer with a scalpel and washed once in $50 \mathrm{ml}$ of sterile HBSS containing antibiotics. The endometrial strips were then minced into small pieces $\left(1 \mathrm{~mm}^{3}\right)$. The minced tissues ( $\sim 5 \mathrm{~g}$ ) were digested by stirring for $60 \mathrm{~min}$ in $50 \mathrm{ml}$ of sterile HBSS containing $0.05 \%(\mathrm{w} / \mathrm{v})$ collagenase (Sigma), 0·005\% (w/v) DNase I (Sigma), and 0·1\% (w/v) BSA. The dissociated cells were filtered through metal meshes $(100 \mu \mathrm{m}$ and $80 \mu \mathrm{m})$ to remove undissociated tissue fragments. The filtrate was washed thrice by centrifugation $(10 \mathrm{~min}$ at $100 \mathrm{~g}$ ) with DMEM (Sigma) supplemented with antibiotics and $0 \cdot 1 \%(\mathrm{w} / \mathrm{v})$ BSA. After the washes, the cells were counted with a hemocytometer. The cell viability was higher than $85 \%$ as assessed by $0.5 \%(\mathrm{w} / \mathrm{v})$ Trypan blue dye exclusion.

\section{Culture of endometrial cells}

The final pellet of the isolated epithelial or stromal cells were resuspended in culture medium (DMEM/Ham's F-12; 1:1 (v/v); Sigma) supplemented with $10 \%$ (v/v) calf serum (CS; Sigma), $20 \mu \mathrm{g} / \mathrm{ml}$ gentamicin (Invitrogen), and $2 \mu \mathrm{g} / \mathrm{ml}$ amphotericin B (Sigma; Skarzynski et al. 2000). The stromal cells were seeded at a density of $1 \times 10^{5}$ viable cells $/ \mathrm{ml}$ in 48 -well cluster dishes (Greiner Bio-One, Frickenhausen, Germany) for experiments 1 and 2, in 24-well cluster dishes (Costar, Cambridge, MA, USA) for experiment 3 , or in $80 \mathrm{~cm}^{2}$ culture flask (Greiner Bio-One) for experiment 4, and the epithelial cells were seeded at a density of $1 \times 10^{5}$ viable cells $/ \mathrm{ml}$ in culture flasks (Nunc) and cultured at $38^{\circ} \mathrm{C}$ in a humidified atmosphere of $5 \% \mathrm{CO}_{2}$ in air. To purify the stromal preparation, the medium was changed $2 \mathrm{~h}$ after plating, by which time selective attachment of stromal cells had occurred (Fortier et al. 1988, Skarzynski et al. 2000). Alternatively, since the epithelial cells attached 24-48 h after plating, the medium was changed every 2 days until the cells reached confluence. When the epithelial cells were confluent, $0 \cdot 02 \%(\mathrm{w} / \mathrm{v})$ trypsin solution was added to the cells to remove the other cells. After removal of the other cells, $0 \cdot 25 \%(\mathrm{w} / \mathrm{v})$ trypsin solution was then added to the epithelial cells to collect the pure epithelial cells. The cells removed, adjusted to a density of $1 \times 10^{5} \mathrm{cells} / \mathrm{ml}$, and placed in 
48-well cluster dishes for DNA quantification in fresh DMEM/ Ham's F-12 supplemented with 10\% (w/v) CS, $20 \mu \mathrm{g} / \mathrm{ml}$ gentamicin, and $2 \mathrm{mg} / \mathrm{ml}$ amphotericin $\mathrm{B}$ until the cells reached confluence. The homogeneity of stromal cells and epithelial cells was evaluated using immunofluorescent staining for specific markers of epithelial (cytokeratin) and stromal cells (vimentin) as described previously (Malayer \& Woods 1998). The epithelial cell contamination of stromal cells was about $1 \%$ and stromal cells contamination of epithelial cells $<1 \%$ (Fig. 1). These values were similar to the results of our previous study (Lee et al. 2007). When cells of each type were confluent (6-7 days after the start of the culture), the medium was replaced with fresh DMEM/Ham's F-12 supplemented with $0 \cdot 1 \%(\mathrm{w} / \mathrm{v})$ BSA, $5 \mathrm{ng} / \mathrm{ml}$ sodium selenite (Sigma), $0.5 \mathrm{mM}$ ascorbic acid (Wako Pure Chemical Industries, Ltd, Osaka, Japan), $5 \mu \mathrm{g} / \mathrm{ml}$ transferrin (Sigma), $2 \mu \mathrm{g} / \mathrm{ml}$ insulin (Sigma), and $20 \mu \mathrm{g} / \mathrm{ml}$ gentamicin. The cells were then exposed to different concentrations of IL1A for $24 \mathrm{~h}$.

Experiment 1 To determine the dose-dependent effects of IL1A and IL1B on PGE2 and PGF2 $\alpha$ production in the bovine epithelial and stromal cells, the cells were exposed to IL1A (0.006-3.0 nM; Dainippon Pharmaceutical Co., Ltd., Osaka,
Japan) or IL1B (0·006-3·0 nM; PeproTech House Co., London, UK) for $24 \mathrm{~h}$. Oxytocin (OT, $100 \mathrm{nM}$; Teikoku Hormone MFG Co., Tokyo, Japan) and tumor necrosis factor- $\alpha$ (TNF, 0.06 nM; Dainippon Pharmaceutical Co., Ltd) was used. The concentrations of OT and TNF were based on a previous study (Skarzynski et al. 2000). We previously reported that TNF stimulates both PG productions in stromal cells but not in epithelial cells (Skarzynski et al. 2000). Thus, TNF was used as a positive control to confirm that endometrial stromal cells were responsive in the present culture system.

Experiment 2 To determine the intracellular mechanisms involved in IL1A actions on PG synthesis by the bovine stromal cells, the cells were exposed to a PLA2 inhibitor (anthranilic acid, ACA; $1 \mu \mathrm{M}$; Calbiochem, San Diego, CA, USA), a PLC inhibitor $(1 \mu \mathrm{M}$; U-73122, Calbiochem; \#662035), AA (10 $\mu \mathrm{M}$; Sigma), or a selective COX2 inhibitor (5 nM; NS-398; BIOMOL, Plymouth Meeting, PA, USA) with IL1A $(0.06 \mathrm{nM})$ or without for $24 \mathrm{~h}$.

After culture, in experiment 1 and experiment 2, the conditioned medium was collected in tubes with $5 \mu \mathrm{l} 0 \cdot 3 \mathrm{M}$ EDTA, 1\% (w/v) aspirin (Sigma) solution ( $\mathrm{pH} 7 \cdot 3$ ), and frozen at $-30{ }^{\circ} \mathrm{C}$ until the $\mathrm{PG}$ assay. The DNA content of the

\section{A Stromal cells}

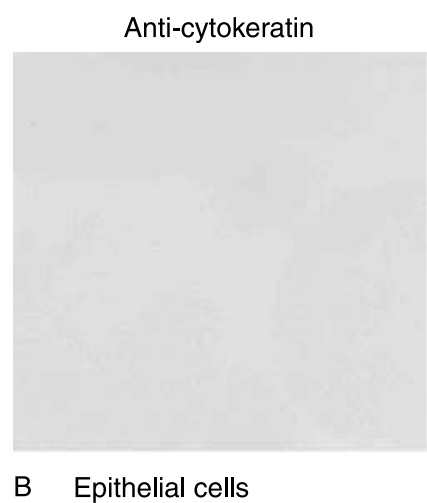

B Epithelial cells Anti-cytokeratin

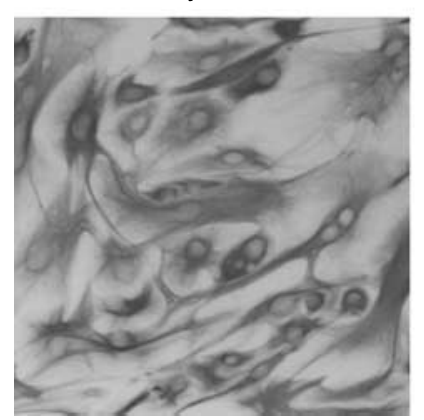

Anti-vimentin

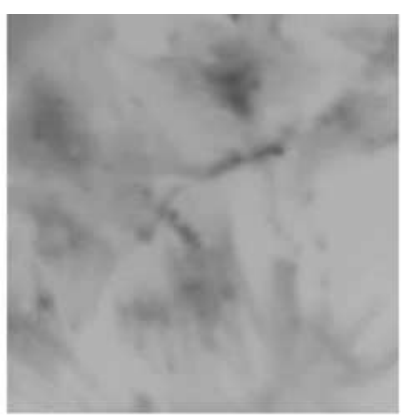

Anti-vimentin

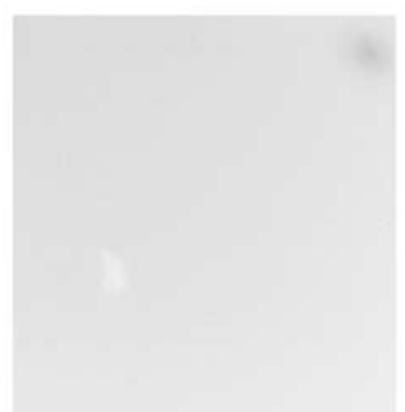

Control

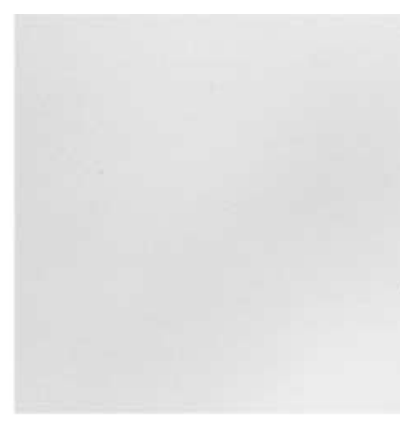

Control

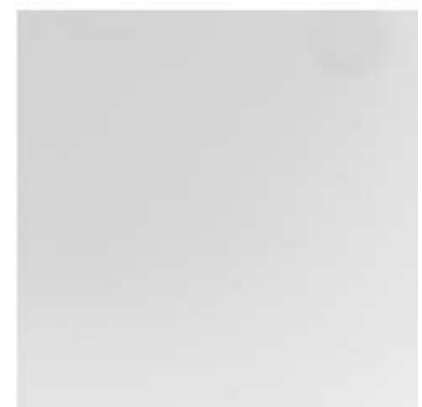

Figure 1 Representative photomicrograph of immunostaining for vimentin and cytokeratin in endometrial (A) stromal and (B) epithelial cells. The cells were incubated with primary antibody against either vimentin (monoclonal anti-vimentin; 1:200 dilution; upper and lower middle) or cytokeratin (monoclonal anti-cytokeratin peptide: 1:100 dilution; upper and lower right), then with second antibody (anti-mouse $\lg$ FITC conjugate-donkey; 1:200 dilution), and were visualized by fluorescence microscopy. Controls were prepared in the absence of primary antibody (upper and lower left). 
epithelial and stromal cells was estimated spectrophotometrically as described by Labarca \& Paigen (1980), to standardize the results. Briefly, after collection of the media, the cells were washed two times with $500 \mu$ l of phosphate-saline buffer (50 nM NaH2PO4 2H2O, $140 \mathrm{nM} \mathrm{NaCl}, 10 \mathrm{mM}$ NaH2PO4, $2 \mathrm{mM}$ EDTA; $\mathrm{pH} 7 \cdot 4)$ and ultrasonicated for $20 \mathrm{~s}$. The samples and standard $(100 \mu \mathrm{l})$ were dispensed in a 96-well plate (Griner Bio-One), and then $40 \mu \mathrm{l}$ of bisbenzimide (8.43 $\mu \mathrm{M}$; Sigma) was added into each well of the plate. After a 10-min incubation at $4{ }^{\circ} \mathrm{C}$, fluorescence was evaluated using a Plate reader, Fluorescence II (Flow Laboratories). The DNA from the calf thymus (Sigma) was used as a standard, and the standard curve was determined for concentrations in the range from $0 \cdot 1$ to $20 \mu \mathrm{g} / \mathrm{ml}$. Since IL1A stimulates PGE2 and PGF2 $\alpha$ production in stromal cells, but not in epithelial cells, experiments 3 and 4 were performed only in stromal cells.

Experiment 3 To determine the effect of IL1A on mRNA expressions of enzymes directly involved in $\mathrm{PG}$ production such as COX1, COX2, PGES1, PGES2, PGES3, and PGFS in bovine stromal cells, cells were exposed to IL1A $(0 \cdot 06 \mathrm{nM})$ for $24 \mathrm{~h}$, disrupted with $1 \mathrm{ml}$ of TRIZOL Reagent (Invitrogen), and frozen at $-80{ }^{\circ} \mathrm{C}$ until determination of the mRNA.

Experiment 4 To determine the effect of IL1A on COX2, PGES1, and PGFS protein expression in bovine stromal cells, the cells were exposed to IL1A $(0.06 \mathrm{nM})$ for $24 \mathrm{~h}$. The cultured cells were scraped and placed in ice-cold homogenization buffer $(25 \mathrm{mM}$ Tris- $\mathrm{HCl}, 300 \mathrm{mM}$ sucrose, $2 \mathrm{mM}$ EDTA, Complete (protease inhibitor cocktail; Roche), $\mathrm{pH}$ $7 \cdot 4$ ), then frozen in liquid nitrogen, and stored at $-80^{\circ} \mathrm{C}$ until protein analysis by western blotting.

\section{PGE2 and PGF $2 \alpha$ determination}

The concentrations of PGE2 and PGF2 $\alpha$ in the culture media were determined with an enzyme immunoassay described previously (Uenoyama et al. 1997, Skarzynski \& Okuda
2000). The PGE2 standard curve ranged from 0.039 to $10 \mathrm{ng} / \mathrm{ml}$, and the ED50 of the assay was $0.625 \mathrm{ng} / \mathrm{ml}$. The intra- and interassay coefficients of variation were on average $10 \cdot 6$ and $7 \cdot 4 \%$ respectively. The crossreactivities of the antiPGE2 serum, validated by comparing the inhibition of binding of peroxidase-labeled PGE2 to antiserum, were as follows: PGE2, 100\%; PGE1, 15\%; PGJ2, 14\%; PGA1, 10\%; PGB2, 6.7\%; PGA2, 4·6\%; PGF2 $\alpha, 2 \cdot 8 \%$; PGD2, $0 \cdot 13 \%$; and $15-$ keto-PGE2, $0 \cdot 05 \%$. The PGF $2 \alpha$ (Sigma) standard curve ranged from $0 \cdot 016$ to $4 \mathrm{ng} / \mathrm{ml}$, and the ED50 of the assay was $0 \cdot 25 \mathrm{ng} / \mathrm{ml}$. The intra- and interassay coefficients of variation were $7 \cdot 3$ and $11 \cdot 2 \%$ respectively.

\section{$R N A$ isolation and $c D N A$ synthesis}

Total RNA was prepared from cultured endometrial cells using TRIZOL Reagent according to the manufacturer's directions (Invitrogen; no. 15596-026). Total RNA (1 $\mu \mathrm{g})$ was reverse transcribed using a ThermoScript RT-PCR System (Invitrogen).

\section{Real-time PCR}

Gene expression was measured by real-time PCR using the Mx3000P QPCR System (Stratagene, La Jolla, CA, USA) and QuantiTect SYBR Green PCR system (Qiagen GmbH) starting with $2 \mathrm{ng}$ of reverse-transcribed total RNA. For quantification of the mRNA expression levels, the primer length $(20 \mathrm{bp})$ and GC contents of each primer (50-60\%) were selected (Table 1), and standard curves of sample cDNA were generated using serial dilutions (1:2 to $1: 1000)$. Expression of GAPDH was used as an internal control. PCR was performed under the following conditions: $95^{\circ} \mathrm{C}$ for $15 \mathrm{~min}$, followed by 55 cycles of $94{ }^{\circ} \mathrm{C}$ for $15 \mathrm{~s}, 55^{\circ} \mathrm{C}$ for $20 \mathrm{~s}$, and $72{ }^{\circ} \mathrm{C}$ for $15 \mathrm{~s}$. Use of the QuantiTect SYBR Green PCR system at elevated temperatures resulted in reliable and sensitive quantification of the RT-PCR products with high linearity (Pearson's correlation coefficient; $r>0 \cdot 99$ ). Each

Table 1 Primers used in real time

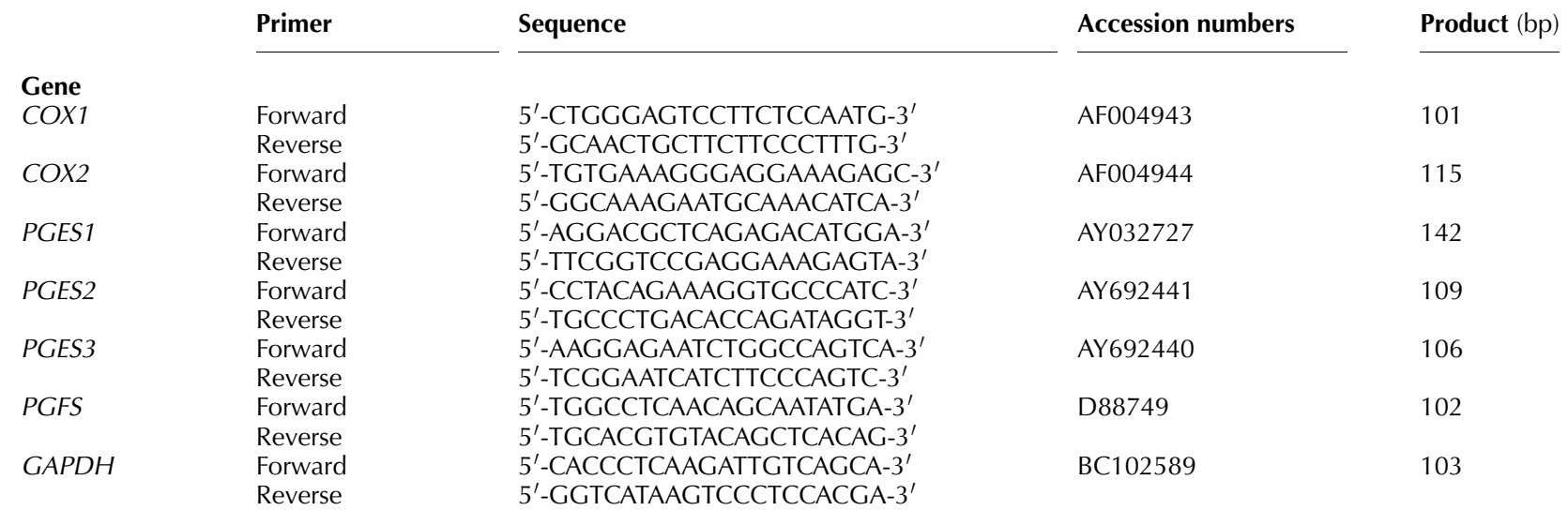


PCR product was sequenced to ensure that the correct mRNA-cDNA was amplified. In addition, dissociation curve analysis was run following each real-time experiment to confirm the presence of only one product and the absence of the formation of primer dimers. The amplification efficiency rate for amplicons averaged over 99\%. Relative concentrations of products are reported as the ratio of the target cDNA amplicon to the DAPDH amplicon, which was used as a loading control.

\section{COX2, PGES1, and PGFS protein analysis}

COX2, PGES1, and PGFS proteins level in cultured bovine endometrial stromal cells was assessed by western blotting analysis. The cultured cells (experiment 4 ) were ultrasonicated on ice and lysed in $100 \mu \mathrm{l}$ of lysis buffer $(20 \mathrm{mM}$ Tris$\mathrm{HCl}, 150 \mathrm{mM} \mathrm{NaCl}, 1 \%$ Triton X-100, 10\% glycerol (Sigma), Complete, $\mathrm{pH} 7 \cdot 4$ ). Protein concentration was determined by the method of Osnes et al. (1993), using BSA as a standard. The proteins were then solubilized in SDS gel loading buffer $(50 \mathrm{mM}$ Tris- $\mathrm{HCl}, 2 \%$ SDS (Nacalai Tesque, Inc., Kyoto, Japan), $10 \%$ glycerol, $1 \% \beta$-mercaptoethanol (Wako Pure Chemical Industries), $\mathrm{pH} 6 \cdot 8$ ), and heated at $95^{\circ} \mathrm{C}$ for $10 \mathrm{~min}$. Samples (50 $\mu$ g protein) were subjected to electrophoresis on a 10\% (COX2 and PGFS) or 15\% (PGES1) SDS-PAGE for $1 \mathrm{~h}$ at $200 \mathrm{~V}$. The separated proteins were electrophoretically transblotted to a $0 \cdot 2 \mu \mathrm{m}$ nitrocellulose membrane (Invitrogen; for COX2 and PGFS or polyvinylidene difluoride membrane (Invitrogen) for PGES1 at $250 \mathrm{~mA}$ for $3 \mathrm{~h}$ in transfer buffer ( $25 \mathrm{mM}$ Tris- $\mathrm{HCl}, 192 \mathrm{mM}$ glycine, $20 \%$ methanol, $\mathrm{pH} 8 \cdot 3)$. The membrane was then washed in TBS-T $(0 \cdot 1 \%$ Tween 20 in TBS $(25 \mathrm{mM}$ Tris- $\mathrm{HCl}, 137 \mathrm{mM}$ $\mathrm{NaCl}, \mathrm{pH} 7 \cdot 5)$ ), and cut into two pieces: one piece was used for a target protein (COX2 (72 kDa), PGES1 (16 kDa), PGFS $(36 \cdot 7 \mathrm{kDa}))$ and another piece was used for GAPDH (internal standard; $40 \mathrm{kDa})$. The pieces for each protein were incubated in blocking buffer $(5 \%$ nonfat dry milk in TBS-T) for $1 \mathrm{~h}$ at $4{ }^{\circ} \mathrm{C}$. After the blocking incubation, the pieces of the membrane were separately incubated with a primary antibody specific to each protein. COX2 antibody (Alpha Diagnostic, San Antonio, TX, USA; 1:2000), PGES1 antibody (Cayman, Ann Arbor, MI, USA; 1:1000), PGFS antibody (kindly donated by Dr Watanabe, Division of Applied Life Sciences, Graduate School of Integrated Sciences and Arts, University of East Asia, Shimonoseki, Yamaguchi, Japan; 1:2000), and GAPDH antibody (Lab Frontier, Seoul, Korea; 1:10 000) in TBS-T, overnight at $4{ }^{\circ} \mathrm{C}$. After incubation, the membrane pieces were washed thrice for $10 \mathrm{~min}$ in TBS-T at room temperature, and then incubated with secondary antibody (anti-rabbit Ig, HRPlinked whole antibody produced in goat, Assay Designs Inc., MI, USA; 1: 10000 in TBS-T) for $1 \mathrm{~h}$, and washed thrice in TBS- $\mathrm{T}$ for $10 \mathrm{~min}$ at room temperature. The signal was detected by pico EPD (enhanced peroxidase detection) Western Blot Detection kit (Mbiotech, Seoul, Korea). The intensity of the immunological reaction in the cells was estimated by measuring the optical density in the defined area by computerized densitometry using NIH Image (National Institutes of Health, USA).

\section{Statistical analysis}

The experimental data are shown as the mean \pm S.E.M. of values obtained from three to four separate experiments. Each experiment was performed in triplicate using endometrial cells obtained from a different cow. The level of PGF2 $\alpha$ or PGE2 production (measured in culture media) was normalized to DNA concentrations and expressed as ng/ $\mu \mathrm{g}$ DNA. The statistical significance of differences between controls and treated group in production of both PGs were assessed by ANOVA followed by a Fisher's protected leastsignificant difference procedure as a multiple comparison test. The statistical significance of differences in the relative amounts of mRNA and proteins was determined using the ratio of the target cDNA amplicon to the GAPDH amplicon and that of the target protein to GAPDH protein respectively, by ANOVA followed by Student's $t$-test.

\section{Results}

Dose-dependent and cell type-specific effects of IL1A and IL1B on PG production

IL1A and IL1B dose-dependently stimulated both PGE2 and PGF $2 \alpha$ production in stromal cells $(P<0 \cdot 05)$, whereas the stimulatory effects of both IL1s were not observed in epithelial cells (Fig. 2). The stimulatory effect of IL1A $(0 \cdot 06-3 \mathrm{nM})$ on both PG production was greater than that of IL1B (Fig. 3A and B) TNF, and OT stimulated the production of both PGE2 and PGF2 $\alpha$ in stromal cells and epithelial cells respectively $(P<0 \cdot 05)$, which accounts for appropriate response of the cells in the present culture system. In contrast to IL1A, OT significantly increased both PGE2 and PGF2 $\alpha$ production in epithelial cells $(P<0 \cdot 05)$, which also accounts for the appropriate response of the epithelial cells. Since the stimulatory effect of IL1A on PG production was clearly greater than that induced by the same dose of IL1B in stromal cells, IL1A was used to further investigate the intracellular mechanisms involved in PG stimulation in endometrial stromal cells.

Effects of PL inhibitors, AA, and COX2 inhibitor on IL1Ainduced $P G$ production in stromal cells

The basal production of both PGs was not influenced by a PLA2 inhibitor (ACA) in stromal cells (Fig. 4). Although a PLC inhibitor (U-73122) showed no significant effects on basal and IL1A-induced PG production, ACA completely blocked the stimulatory action of IL1A $(P<0 \cdot 05)$. Arachidonic acid increased basal PG production in stromal cells. Moreover, the stimulatory effect of IL1A on production of 
Stromal cells
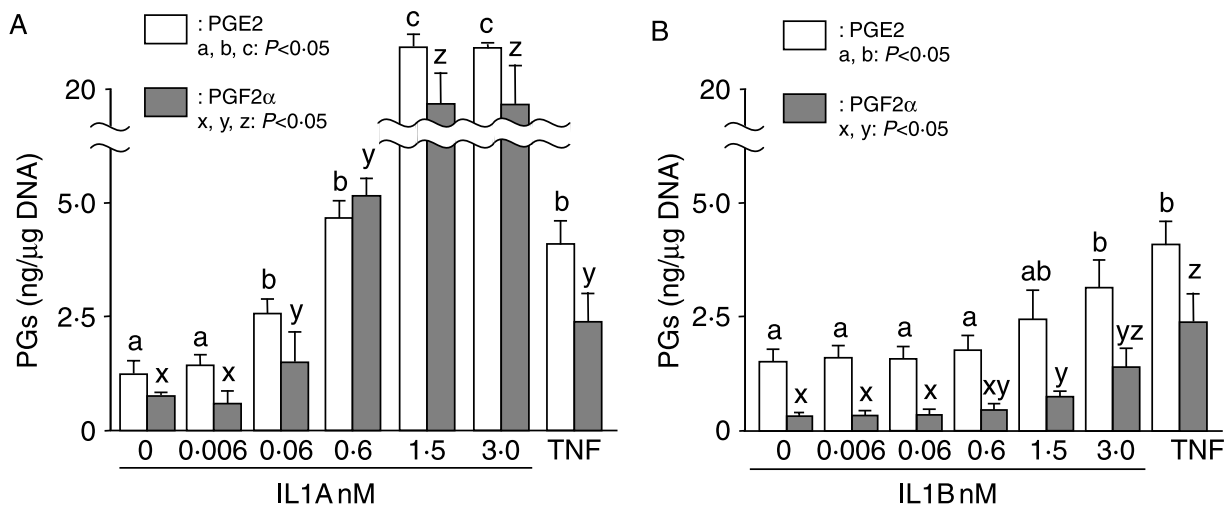

Epithelial cells
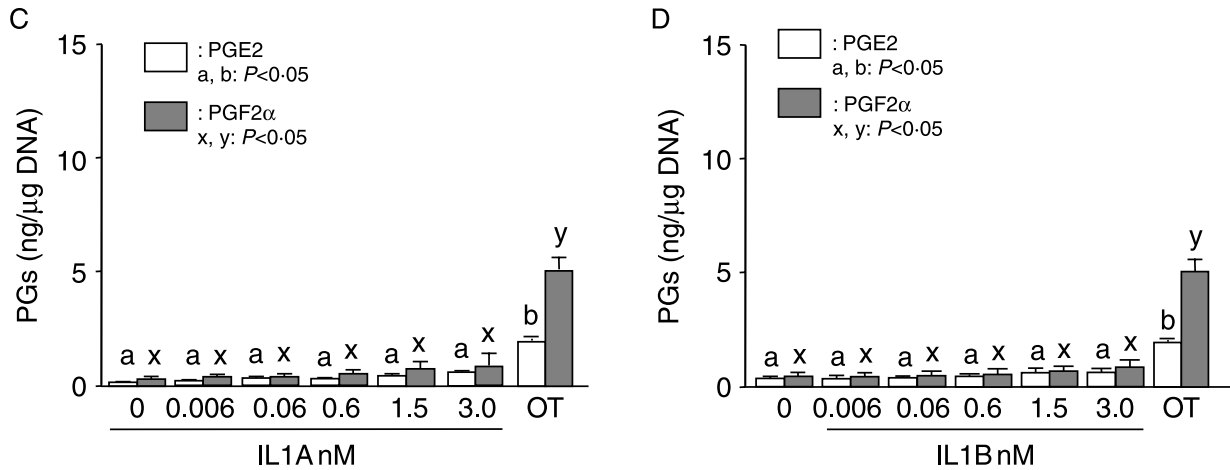

Figure 2 Effects of (A and C) IL1A and(B and D) IL1B on PGE2 (white bars) and PGF2 $\alpha$ (gray bars) production by (A and B) cultured bovine stromal and (C and D) epithelial cells. IL1A or IL1B $(0 \cdot 006-3 \cdot 0 \mathrm{nM})$ was added $24 \mathrm{~h}$ before the end of culture. Experiments with isolated cells were performed three times each with separate cell preparations. Data are the mean \pm S.E.M. of three separate experiments. Different superscript letters $a, b, c$ (PGE2) and $x, y, z$ (PGF2 $\alpha)$ indicated significant differences $(P<0 \cdot 05)$, as determined by ANOVA followed by a Fisher's PLSD as a multiple comparison test.

both PGs was augmented by AA $(P<0 \cdot 001)$. IL1A-induced production of $\mathrm{PG}$ was blocked by a specific COX2 inhibitor (NS-398; $P<0 \cdot 05$ ), whereas NS-398 showed no significant effect on basal PG production (Fig. 4).

Effects of IL1A on COX1, COX2, PGES1, PGES2, PGES3, and PGFS gene expressions in stromal cells

IL1A $(0.06 \mathrm{nM})$ increased the mRNA expressions of COX2 (Fig. 5B) and PGES1 (Fig. 5C), whereas IL1A did not affect the expression of COX1, COX2, PGES3, and PGFS mRNA in stromal cells (Fig. 5A, D and F).

Effects of IL1A on COX2, PGES1, and PGFS protein levels in stromal cells

Specific bands of COX2, PGES1, and PGFS were expressed in stromal cells (Fig. 6A-C), in agreement with a previous result (Woclawek-Potocka et al. 2005). Intensities of the bands, after normalization to GAPDH-specific bands, showed that IL1A $(0.06 \mathrm{nM})$ increased COX2 and PGES1 protein expression in stromal cells (Fig. 6A and $\mathrm{B} ; P<0 \cdot 05$ ). PGFS protein expression in bovine stromal cells was not stimulated by IL1A (Fig. 6C).

\section{Discussion}

The present study demonstrated that IL1A stimulates PGE2 and PGF $2 \alpha$ production in the stromal cells, but not in the epithelial cells of the bovine endometrium, and that PLA2 and COX2 are directly involved in the stimulatory actions of IL1A on both PGE2 and PGF $2 \alpha$ production. These findings suggest that IL1A regulates the production of bovine uterine PGE2 and PGF2 $\alpha$, mainly in endometrial stromal cells by regulating key enzymes involved in PG biosynthesis.

IL1B is an isomer of IL1A that acts through the same receptor as IL1A and has similar biological activity (Dinarello 1988, 1991). IL1B stimulated the production of PG in endometrial stromal and epithelial cells isolated from bovine endometrium exposed to high levels of progesterone on day 16 of pregnancy (Betts \& Hansen 1992) and on day 11 or 14 of the estrous cycle 

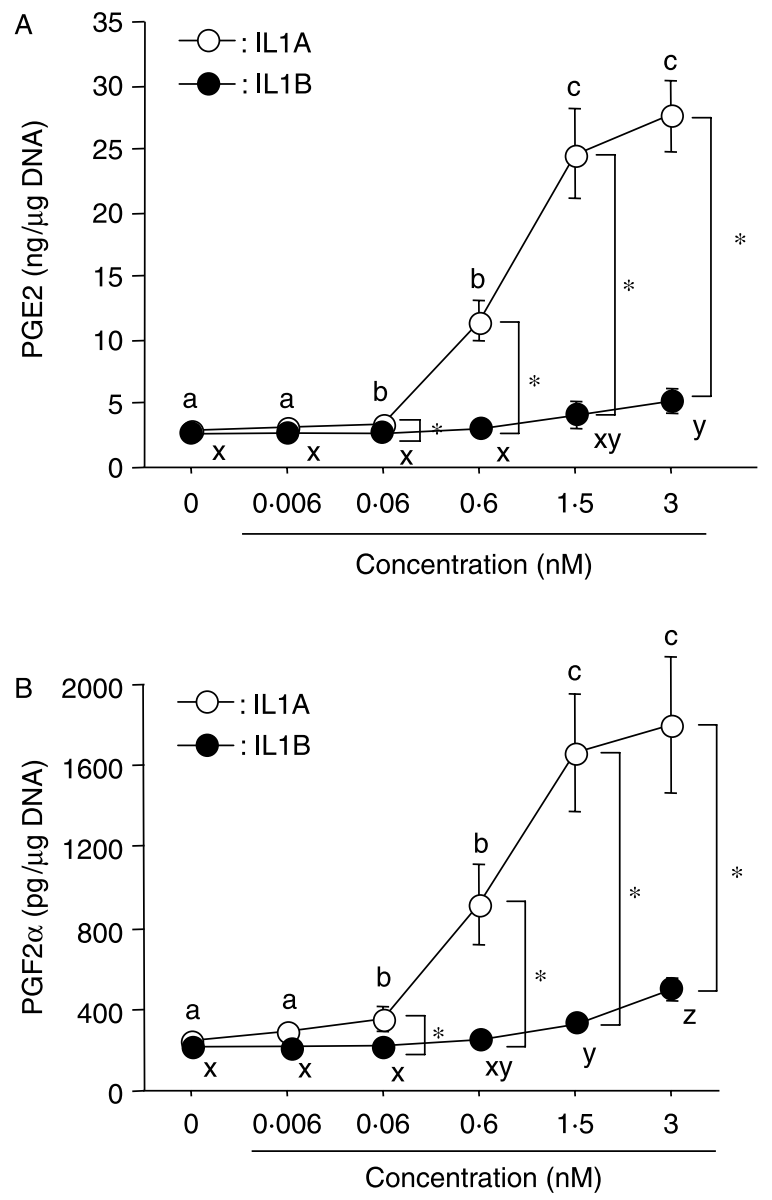

Figure 3 Effect of IL1A $(O)$ and IL1B (O) on (A) PGE2 and (B) PGF2 $\alpha$ production in cultured bovine endometrial stromal cells. IL1A and IL1B $(0 \cdot 006-3 \mathrm{nM})$ were added $24 \mathrm{~h}$ before the end of culture. Asterisks indicate a significant difference in PG production between cells treated with the same dose of IL1A and IL1B, as determined by ANOVA followed by Student's $t$-test. Different superscript letters: $a, b, c$ (IL1A) and $x, y, z$ (IL1B) indicate significant differences between treated and untreated cells $(P<0 \cdot 05)$, as determined by ANOVA followed by a Fisher's PLSD as a multiple comparison test.

(Davidson et al. 1995). However, the effects of IL1A on PG production were not analyzed. Using endometrial cells that were isolated from the uterus between days 2 and 5 after estrus, and that were exposed to high levels of estradiol, we demonstrated that IL1 has a cell type-specific action affecting PG production in stromal cells, but not in epithelial cells. The discrepancy between the results of the present and previous studies may be due to the different time of exposure to estradiol (present study) and progesterone (former studies). However, in the preliminary experiment, we found that the stage of the estrous cycle has a minimum effect on the secretory response of endometrial cells in the present culture system. In addition, the human recombinant IL1A and IL1B used in the present study dose-dependently increased PGF2 $\alpha$ and PGE2 production by
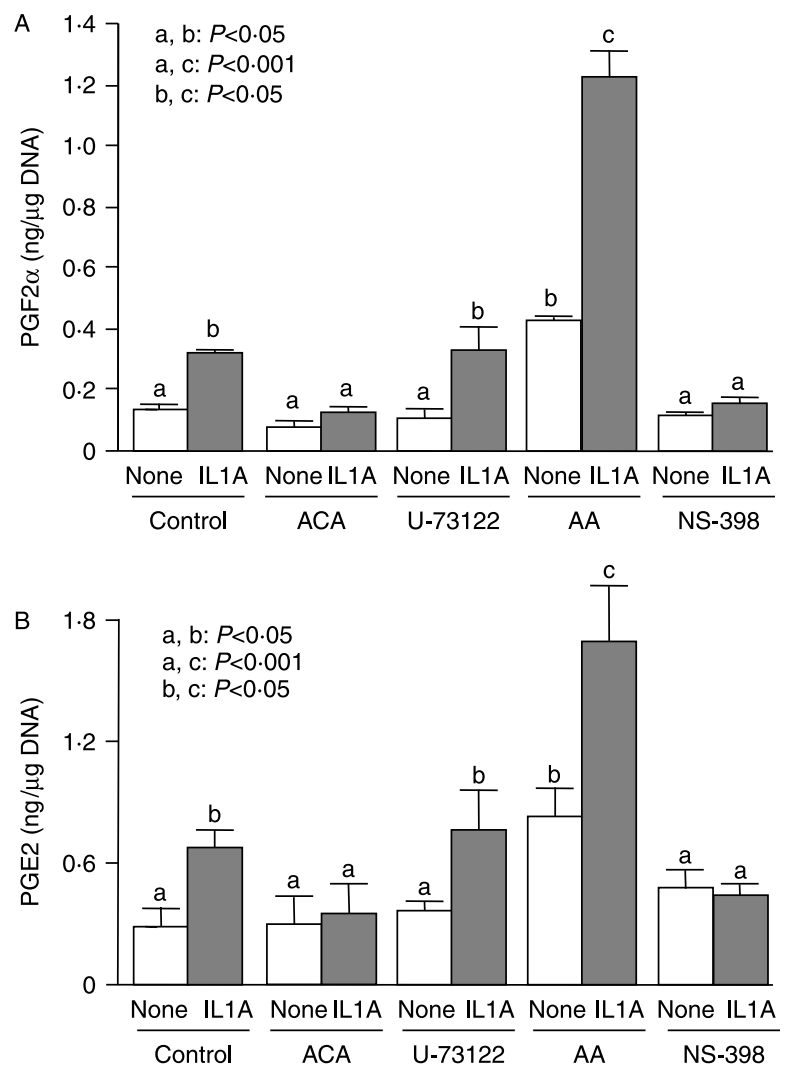

Figure 4 Effects of ACA (a PLA2 inhibitor), U-73122 (a PLC inhibitor) AA and NS-398 (a COX2 inhibitor) on IL1A-stimulated (A) PGF $2 \alpha$ and (B) PGE2 production by stromal cells. ACA $(1 \mu \mathrm{M})$, U-73122 $(1 \mu \mathrm{M})$, AA $(10 \mu \mathrm{M})$, NS-398 $(5 \mathrm{nM})$, and IL1A $(0 \cdot 06 \mathrm{nM})$ were added $24 \mathrm{~h}$ before the end of culture. Experiments with isolated cells were performed three times each with separate cell preparations. Data are the mean \pm s.E.M. of three separate experiments. Different superscript letters indicate significant differences $(P<0 \cdot 05)$, as determined by ANOVA followed by a Fisher's PLSD as a multiple comparison test.

the luteal cells of all stages in our previous study (Nishimura et al. 2004). Thus, the differences in the cell-specific response of cultured bovine endometrial cells to IL1A and IL1B were not due to differences in the specific activity of the human recombinant IL1. Since the stimulatory effect of IL1A on PG was clearly greater than that induced by the same dose of IL1B in stromal cells, IL1A was used to further investigate the intracellular mechanisms involved in PG stimulation in endometrial stromal cells.

IL1 activates cellular responses by interacting with a signaling receptor complex formed by a functional receptor, IL1R type I (IL1RT1). IL1R type II (IL1RT2), a decoy receptor acts as a negative pathway of regulation of IL1, can more efficiently bind to IL1B than IL1A (Arend 1991, Colotta et al. 1994, Boraschi et al. 1996). Thus, the results of the present and previous studies raise the possibility that IL1A exerts a more potent effect than the same dose of IL1B due to a decrease in the amount of IL1B which can bind IL1RT1 in 

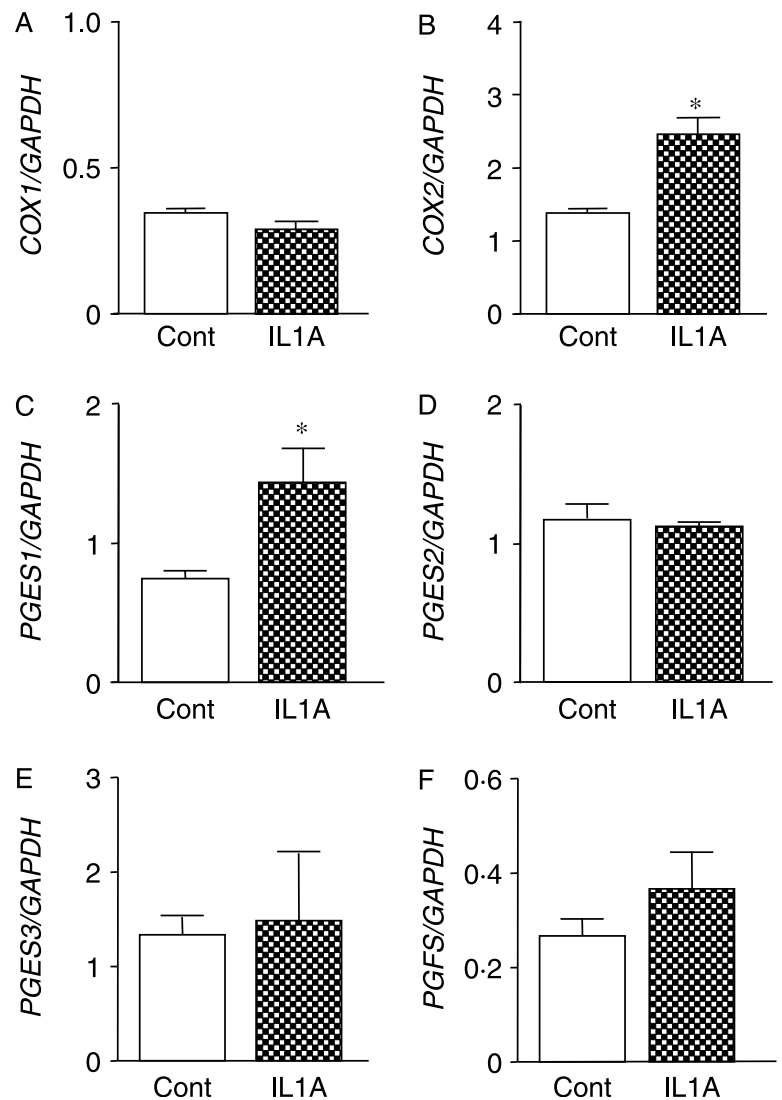

Figure 5 Effects of IL1A on the amounts of (A) COX1, (B) COX2, (C) PGES1, (D) PGES2, (E) PGES3, and (F) PGFS mRNA expression in cultured bovine stromal cells. IL1A $(0.06 \mathrm{nM})$ was added $24 \mathrm{~h}$ before the end of culture. Experiments with isolated cells were performed three times each with separate cell preparations. Data are the mean \pm S.E.M. of three separate experiments, and are expressed as the relative levels to GAPDH mRNA levels. Asterisk indicates significant differences $(P<005)$, as determined by ANOVA followed by Student's $t$-test.

the stromal cells. However, since the expression of IL1RT2 in bovine endometrium is still unclear, further studies are needed to clarify these points.

PGs are produced from AA liberated from phospholipid stores through the action of PLs (Burgoyne \& Morgan 1990). In the present study, an inhibitor of PLA2 (ACA) completely stopped the stimulatory action of IL1A, whereas an inhibitor of PLC (U-73122) did not significantly affect IL1A-induced PG production. The failure of IL1A action on stimulating PG production in the stromal cells treated with ACA may be due to a lower accumulation of AA. This supposition is supported by the fact that exogenous AA strongly augmented IL1Astimulated PG production, suggesting that IL1A influences the downstream of AA cascade metabolized by PLA2 in the PG biosynthesis pathways.

COX2 is an inducible key rate-limiting enzyme for converting AA to the unstable form of PGs, PGG2/PGH2, which is the first step in the synthesizing of PGs (Morita 2002,
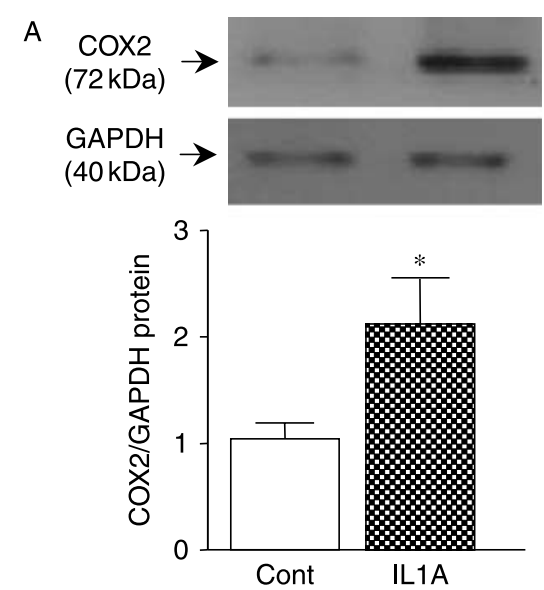

B
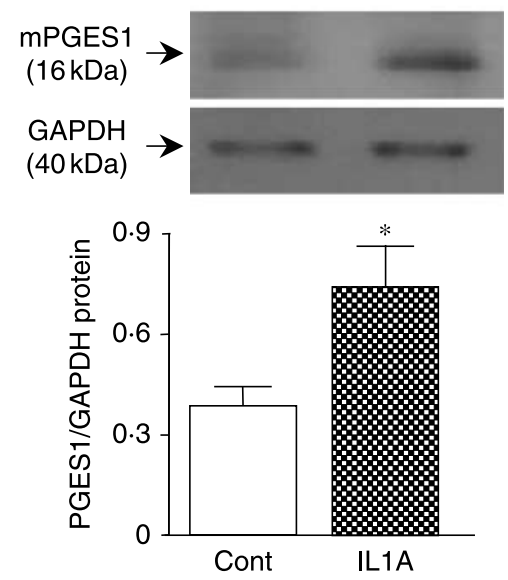

C
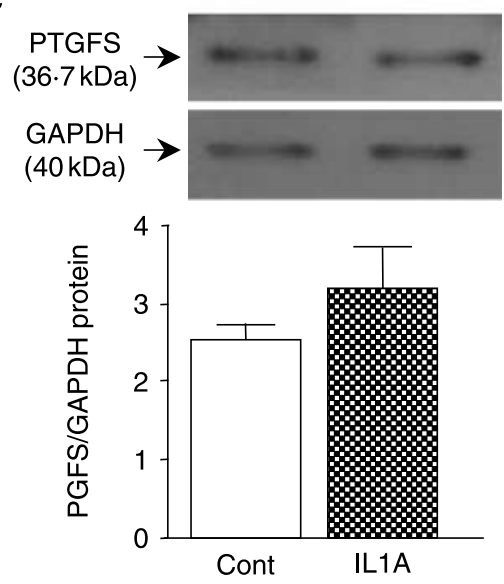

Figure 6 Effects of IL1A on COX2, PGES1, and PGFS protein levels in cultured bovine stromal cells. IL1A $(0.06 \mathrm{nM})$ was added $24 \mathrm{~h}$ before the end of culture. Experiments with isolated cells were performed three times each with separate cell preparations. Representative samples of western blot for (A) COX2, (B) PGES1, (C) PGFS and GAPDH are shown in upper panels. Data are the mean \pm S.E.M. of four separate experiments, and are expressed as the relative ratio of (A) COX2, (B) PGES1, (C) PGFS protein to GAPDH protein. Asterisk indicates significant differences $(P<0 \cdot 05)$ among treatments, as determined by ANOVA followed by Student's $t$-test. 
Tanabe \& Tohnai 2002). In the present study, IL1A stimulated COX2 expressions and increased the production of both PGs in bovine endometrial stromal cells. Moreover, a specific inhibitor of COX2 (NS-398) blocked IL1A-stimulated PG synthesis in the stromal cells. These findings suggest that the increase in both PGF2 $\alpha$ and PGE2 production induced by IL1A is due to increasing COX2 expression and activating this enzyme.

The bovine endometrium has been shown to express three different isoforms of PGE synthase (PGES1, PGES2, and PGES3). PGES1 seems to be the main PGE synthase responsible for increasing PGE2 production in endometrial cells (Parent \& Fortier 2005). In the present study, although IL1A increased PGES1 mRNA and protein expression concomitant with COX2, it did not affect PGES2 and PGES3 mRNA. Thus, IL1A seems to stimulate PGE2 biosynthesis in bovine endometrial stromal cells via stimulating inducible COX2 and PGES1 expression.

Some genes have been brought as candidates for regulating PGF $2 \alpha$ synthesis in bovine endometrial cells. Madore et al. (2003) showed that $20 \alpha$-hydroxysteroid dehydrogenase (AKR1B5) possesses potent PTGFS activity. Furthermore, they showed another gene expression that is related to PGF2 $\alpha$ production, PGF2 $\alpha$-like 2 synthase (PGFSL2). The specific stimulatory effects of OT in endometrial epithelial cells and TNF in endometrial stromal cells on PGF $2 \alpha$ production have also been demonstrated to be caused via an increase in PGFSL2 gene and protein expressions (Woclawek-Potocka et al. 2005). However, in the present study, IL1A did not affect the mRNA expression of AKR1B5 and PGFSL2 in bovine stromal cells (data not shown). Then, we focused on bovine liver-type PGFS, which cDNA (GenBank accession no. D88749) shared 94\% identity with bovine PGFSL2 (GenBank accession no. AY135401) and both genes belong to the AKRC1 family (Madore et al. 2003). Though in the present study, the expression of PGFS mRNA and protein was detected, the stimulation effect of IL1A on PGFS gene and protein expression was not observed in stromal cells in spite of that IL1A-induced PGF2 $\alpha$ production was demonstrated in stromal cells. Thus, it is thought that IL1A induced PGF $2 \alpha$ production is only via COX2.

The overall results indicate that (1) the target of IL1A and IL1B for stimulating both PGE2 and PGF2 $\alpha$ production is the stromal cells, (2) IL1A is far more potent stimulator than IL1B on PG production in stromal cells, (3) the stimulatory effect of IL1A on PG production is mediated via the activation of PLA2 and COX2, and (4) IL1A induced PG production by increasing expressions of COX2 and PGES1 mRNAs and their proteins in bovine stromal cells.

\section{Declaration of interest}

The authors declare that there is no conflict of interest that could be perceived as prejudicing the impartiality of the research reported.

\section{Funding}

This research was supported by Grant-in-Aid for Scientific Research (no. 14360168, no. 18380166, and no. 19580326) of the Japan Society for the Promotion of Science (JSPS), the Polish Academy of Sciences (PAS), the Japanese-Polish Joint Research Project under an agreement between JSPS and PAS, the Grant of the Polish Ministry of Science and Higher Education (no. 2 P06 K02529) and by the Research Fund from the Livestock Technology Association (LTA), Japan.

\section{Acknowledgements}

We thank the Dainippon Pharmaceutical Co., Ltd for recombinant human IL1A, and Tsuyoshi Fukui for technical assistance, and Dr Seiji Ito of Kansai Medical University, Osaka, Japan for antisera of PGE2 and PGF2 $\alpha$.

\section{References}

Arend WP 1991 Interleukin 1 receptor antagonist. A new member of the interleukin 1 family. Journal of Clinical Investigation 88 1445-1451.

Asselin E, Goff AK, Bergeron H \& Fortier MA 1996 Influence of sex steroids on the production of prostaglandins $\mathrm{F} 2 \alpha$ and $\mathrm{E} 2$ and response to oxytocin in cultured epithelial and stromal cells of the bovine endometrium. Biology of Reproduction 54 371-379.

Asselin E, Drolet P \& Fortier MA 1997 Cellular mechanisms involved during oxytocin-induced prostaglandin F2 $\alpha$ production in endometrial epithelial cells in vitro: role of cyclooxygenase-2. Endocrinology 138 4798-4805.

Bah MM, Acosta TJ, Pilawski W, Deptula K, Okuda K \& Skarzynski DJ 2006 Role of intraluteal prostaglandin $\mathrm{F} 2 \alpha$, progesterone and oxytocin in basal and pulsatile progesterone release from developing bovine corpus luteum. Prostaglandins \& Other Lipid Mediators 79 218-229.

Betts JG \& Hansen PJ 1992 Regulation of prostaglandin secretion from epithelial and stromal cells of the bovine endometrium by interleukin- $1 \beta$, interleukin-2, granulocyte-macrophage colony stimulating factor and tumor necrosis factor- $\alpha$. Life Sciences 51 171-176.

Boraschi D, Bossu P, Macchia G, Ruggiero P \& Tagliabue A 1996 Structurefunction relationship in the IL-1 family. Frontiers in Bioscience: A Journal and Virtual Library 1 270-308 (Review).

Burgoyne RD \& Morgan A 1990 The control of free arachidonic acid levels. Trends in Biochemical Sciences 15 365-366.

Colotta F, Dower SK, Sims JE \& Mantovani A 1994 The type II 'decoy' receptor: a novel regulatory pathway for interleukin 1. Immunology Today $\mathbf{1 5}$ 562-566.

Davidson JA, Tiemann U, Betts JG \& Hansen PJ 1995 DNA synthesis and prostaglandin secretion by bovine endometrial cells as regulated by interleukin-1. Reproduction, Fertility, and Development 7 1037-1043.

Dinarello CA 1988 Biology of interleukin 1. FASEB Journal 2 108-115.

Dinarello CA 1991 Interleukin 1 and interleukin 1 antagonism. Blood 77 1627-1652.

Fortier MA, Guilbault LA \& Grasso F 1988 Specific properties of epithelial and stromal cells from the endometrium of cows. Journal of Reproduction and Fertility 83 239-248.

Kim JJ \& Fortier MA 1995 Cell type specificity and protein kinase C dependency on the stimulation of prostaglandin E2 and prostaglandin F2 $\alpha$ production by oxytocin and platelet-activating factor in bovine endometrial cells. Journal of Reproduction and Fertility 103 239-247.

Labarca C \& Paigen K 1980 A simple, rapid, and sensitive DNA assay procedure. Biochemistry 102 344-352.

Lee HY, Acosta TJ, Tanikawa M, Sakumoto R, Komiyama J, Tasaki Y, Piskula M, Skarzynski DJ, Tetsuka M \& Okuda K 2007 The role of glucocorticoid in the regulation of prostaglandin biosynthesis in non-pregnant bovine endometrium. Journal of Endocrinology 193 127-135. 
Madore E, Harvey N, Parent J, Chapdelaine P, Arosh JA \& Forteir MA 2003 An aldose reductase with $20 \alpha$-hydroxysteroid dehydrogenase activity is most likely the enzyme responsible for the production of prostaglandin F2 $\alpha$ in the bovine endometrium. Journal of Biological Chemistry 278 11205-11212.

Malayer JR \& Woods VM 1998 Expression of estrogen receptor and maintenance of hormone-responsive phenotype in bovine fetal uterine cells. Domestic Animal Endocrinology 15 141-154.

Miyamoto Y, Skarzynski DJ \& Okuda K 2000 Is tumor necrosis factor- $\alpha$ a trigger for the initiation of endometrial prostaglandin F2 $\alpha$ release at luteolysis in cattle? Biology of Reproduction 62 1109-1115.

Morita I 2002 Distinct functions of COX-1 and COX-2. Prostaglandins $\&$ Other Lipid Mediators 68-69 165-175.

Murakami S, Miyamoto Y, Skarzynski DJ \& Okuda K 2001 Effect of tumor necrosis factor- $\alpha$ on secretion of prostaglandin E2 and F2 $\alpha$ in bovine endometrium throughout the estrous cycle. Theriogenology $\mathbf{5 5}$ $1667-1678$

Nishimura R, Bowolaksono A, Acosta TJ, Murakami S, Pitrowska K, Skarzynski DJ \& Okuda K 2004 Possible role of interleukin-1 in the regulation of bovine corpus luteum throughout the luteal phase. Biology of Reproduction 71 1688-1693.

Okuda K, Miyamoto Y \& Skarzynski DJ 2002 Regulation of endometrial prostaglandin F2 $\alpha$ synthesis during luteolysis and early pregnancy in cattle. Domestic Animal Endocrinology 23 255-264.

Osnes T, Sandstad O, Skar V, Osnes M \& Kierulf P 1993 Total protein in common duct bile measured by acetonitrile precipitation and a micro bicinchoninic acid (BCA) method. Scandinavian Journal of Clinical and Laboratory Investigation $\mathbf{5 3}$ 757-763.

Parent J \& Fortier MA 2005 Expression and contribution of three different isoforms of prostaglandin E synthase in the bovine endometrium. Biology of Reproduction 73 36-44.

Paula-Lopes FF, de Moraes AA \& Hansen PJ 1999 The presence of interleukin- $1 \beta$ in the bovine reproductive tract. Journal of Interferon $\mathcal{E}$ Cytokine Research 19 279-285.

Reynold LP, Stigler J, Hoyer GL, Magness RR, Huie JM, Huecksteadt TP, Whysong GL, Behrman HR \& Weems CW 1981 Effect of PGE1 or PGE2 on PGF2 $\alpha$-induced luteolysis in nonbred ewes. Prostaglandins 21 957-972.
Skarzynski DJ \& Okuda K 2000 Different actions of noradrenaline and nitric oxide on the output of prostaglandins and progesterone in cultured bovine luteal cells. Prostaglandins \& Other Lipid Mediators $6035-47$.

Skarzynski DJ, Miyamoto Y \& Okuda K 2000 Production of prostaglandin F2 $\alpha$ by cultured bovine endometrial cells in response to tumor necrosis factor $\alpha$ : cell type specificity and intracellular mechanisms. Biology of Reproduction 62 1116-1120.

Tanabe T \& Tohnai N 2002 Cyclooxygenase isozymes and their gene structures and expression. Prostaglandins \& Other Lipid Mediators 68-69 95-114.

Tanikawa M, Acosta TJ, Fukui T, Murakami S, Kozrekwa A, Skarzynski DJ, Piotrowska KK, Park CK \& Okuda K 2005 Regulation of prostaglandin synthesis by interleukin- $1 \alpha$ in bovine endometrium during the estrous cycle. Prostaglandins \& Other Lipid Mediators 78 279-290.

Townson DH \& Pate JL 1994 Regulation of prostaglandin synthesis by interleukin-1 beta in cultured bovine luteal cells. Biology of Reproduction $\mathbf{5 1}$ 480-485.

Uenoyama Y, Hattori S, Miyake M \& Okuda K 1997 Up-regulation of oxytocin receptors in porcine endometrium by adenosine $3^{\prime}, 5^{\prime}-$ monophosphate. Biology of Reproduction 57 723-728.

Weems YS, Lammoglia MA, Vera-Avila HR, Randel RD, King C, Sasser RG \& Weems CW 1998 Effect of luteinizing hormone (LH), PGE2, 8-EPI-PGE1, 8-EPI-PGE2, trichosanthin, and pregnancy specific protein B (PSPB) on secretion of progesterone in vitro by corpora lutea $(\mathrm{CL})$ from non-pregnant and pregnant cows. Prostaglandins \& Other Lipid Mediators 55 27-42.

Woclawek-Potocka I, Okuda K, Acosta TJ, Korzekwa A, Pilawski W \& Skarzynski DJ 2005 Phytoestrogen metabolites are much more active than phytoestrogens themselves in increasing prostaglandin F2 $\alpha$ synthesis via prostaglandin F2 $\alpha$ synthase-like 2 stimulation in bovine endometrium. Prostaglandins \& Other Lipid Mediators 78 202-217.

Received in final form 23 September 2008

Accepted 25 September 2008 Made available online as an Accepted Preprint 29 September 2008 